Article

\title{
Build Size and Orientation Influence on Mechanical Properties of Powder Bed Fusion Deposited Titanium Parts
}

\author{
Kateřina Mertová ${ }^{1, *}{ }^{\oplus}$, Ján Džugan ${ }^{1}\left(\mathbb{C}\right.$, Michaela Roudnická ${ }^{2}$, Matěj Daniel ${ }^{3}$, Dalibor Vojtěch ${ }^{2}$, \\ Mohsen Seifi ${ }^{4,5}$ (D) and John J. Lewandowski ${ }^{4}$ (D) \\ 1 COMTES FHT a.s., Prumyslova 995, 33441 Dobrany, Czech Republic; jdzugan@comtesfht.cz \\ 2 VSCHT Praha, Technicka 5, 16628 Prague, Czech Republic; michaela.roudnicka@vscht.cz (M.R.); \\ Dalibor.Vojtech@vscht.cz (D.V.) \\ 3 CVUT, Technicka 4, 16000 Prague 6, Czech Republic; Matej.Daniel@fs.cvut.cz \\ 4 Department of Materials Science and Engineering, Case Western Reserve University, \\ Cleveland, OH 44106, USA; mohsen.seifi@case.edu (M.S.); JJL3@case.edu (J.J.L.) \\ 5 ASTM International, Washington, DC 20036, USA \\ * Correspondence: kmertova@comtesfht.cz; Tel.: +420-377-197-366
}

Received: 7 September 2020; Accepted: 27 September 2020; Published: 7 October 2020

\begin{abstract}
This paper explores the influence of sample thickness and build orientation on the microstructure and mechanical properties of electron beam melting (EBM) additive manufactured Ti-6Al-4V titanium alloy and compared to previously published work on SLM-processed material. In particular, the various mechanical properties (tensile yield strength, ultimate tensile strength) were investigated with attempts to correlate with various microstructural features, including lamellae thickness, porosity and the size of prior-beta grains. However, it is shown that the surface exerts a dominant effect on mechanical properties with as-deposited surfaces. These observations provide the possibility for the further improvement of processing/property relations with as-deposited surfaces.
\end{abstract}

Keywords: Ti-6Al-4V; electron beam melting; selective laser melting

\section{Introduction}

Additive manufacturing (AM) has recently become a very popular and widely used method of component production as it offers many advantages in comparison to conventional methods of metal manufacturing. In particular, it can be cost-effective for small batches, is environmentally friendly and time-saving, while providing almost no restrictions on shape, (desired) porosity, or dimensional requirements [1,2]. The design flexibility of the AM process has been frequently used in the production of patient-specific implantable medical devices from titanium and its alloys due to its good mechanical properties, excellent corrosion resistance, biocompatibility and osteointegration properties [2-6].

Titanium implants are mostly manufactured by a powder bed fusion process like selective laser melting (SLM) or electron beam melting (EBM). During these processes, a roller or a blade spreads thin powder layers on the build plane and metal powder is melted and fused together into a solid bulk material, layer by layer, using a laser (e.g., SLM) or electron beam (e.g., EBM). The EBM method requires a vacuum chamber while SLM is usually conducted in an inert-gas protective atmosphere. The SLM technique produces components with a lower surface roughness but higher residual stresses compared to EBM [7], requiring post-processing (e.g., stress-relief) of SLM parts. In contrast, the bed preheat used with EBM can significantly reduce residual stresses while the higher power typically used also provides the possibility of vaporization of volatile species. 
The effect of build parameters, position within the chamber, or sample orientation for both SLM and EBM have been described in multiple studies [1,2,4,8-12]. However, most of the studies have been based on standardized specimen sizes that are quite large. Such large test specimens might not capture the spatial variations present in the build chamber and might not be suitable for studying the properties of relatively thin components frequently produced by AM $[13,14]$.

Several papers $[13,15-18]$ have focused on the benefits of using miniature specimens to assess the mechanical properties of AM products and it has been shown that small specimens can capture and mimic the local differences in deposited parts. Furthermore, small specimens could be manufactured along with products and serve as witness samples as part of a quality assessment process. Therefore, there exists a demand to determine the potential of using small specimens to efficiently analyze the effects of build location and orientation of AM parts $[13,15,19,20]$ on subsequent performance. However, in order to effectively capture these effects of current interest, it is presently not clear how small to make the thin specimens. This also reflects a current lack of knowledge regarding the general effects of sample size on mechanical performance in AM parts/structures.

This paper deals with Ti-6Al-4V examined in the EBM as-deposited condition with a primary goal to reveal the influence of the thickness of small specimens on their microstructure and mechanical properties. The approach utilizes tension testing of small cylindrical and rectangular specimens with different cross sections built in different chamber locations. While the EBM samples were tested in the as-deposited condition, previous work [13] is included for comparison where similar experiments were conducted on SLM samples that were also stress relieved by thermal post-processing to reduce residual stresses. This comparison is important to provide because EBM and SLM processing provides different options for additive manufacturing along with the potential need for post-processing to achieve acceptable properties. In the previous work on SLM-processed material [13] without any powder bed pre-heat, the residual stresses and non-equilibrium microstructures in the as-deposited material were modified by heat treatment as summarized in this paper. The present work on EBM-processed material did not use any post-processing as the high powder bed preheat produces much slower cooling compared to SLM-processed material, resulting in much lower residual stresses and more equilibrium microstructures. It is important to note that the present results and those compared to the SLM-processed material [13] are only valid within the confines of the present methodology and layout since EBM and SLM are very different techniques. The coupling mechanisms between the energy sources and the powder bed are completely different. However, it remains important to determine the effects of these different processes on the resulting properties, similar to what has been done for comparisons between different casting and/or deformation processing techniques.

Tension specimens were tested in either the as-deposited (i.e., rough) or machined conditions and the mechanical properties (tensile yield strength, ultimate tensile strength, and elongation) were compared with microstructural features, such as lamellae thickness, porosity, and the thickness of prior- $\beta$ grains determined by metallographic and fractographic analyses.

\section{Experimental Methods}

\subsection{Processing and Specimen Preparation}

The tensile test specimens of Ti-6Al-4V were produced using EBM. Round and flat specimen designs used in this work, shown schematically in Figure 1, conform to an evolving ASTM standard [21], while the flat specimen dimensions are provided in Figure 2. As this study focused on small specimen testing, the flat specimen thicknesses ranged from $0.5 \mathrm{~mm}$ to $3.0 \mathrm{~mm}$, and the round specimen diameters ranged from $1.0 \mathrm{~mm}$ to $6.0 \mathrm{~mm}$. The EBM deposition scheme in Figure 1 shows the arrangement of specimens in the build chamber, specimen orientations, thickness/diameter values, and specimen identifications. The present work primarily reports the effects of changes in build orientations for the EBM samples because recent similar work has already been published for SLM [13], although comparisons will be provided throughout this paper. 


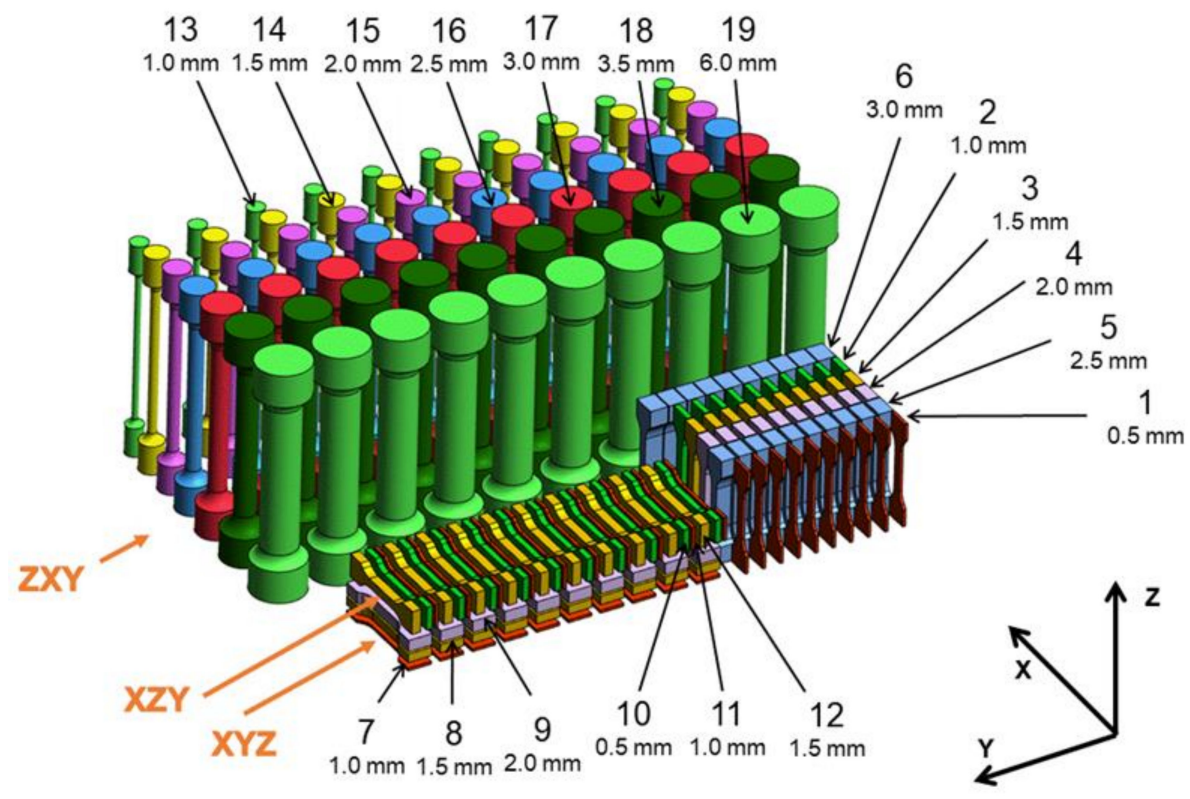

Figure 1. Deposition scheme for the EBM-processed samples. The number designations denote both the sample group and the size, i.e., diameter or thickness for the round and the flat specimens, respectively. A similar scheme was utilized for the SLM-processed samples summarized elsewhere.

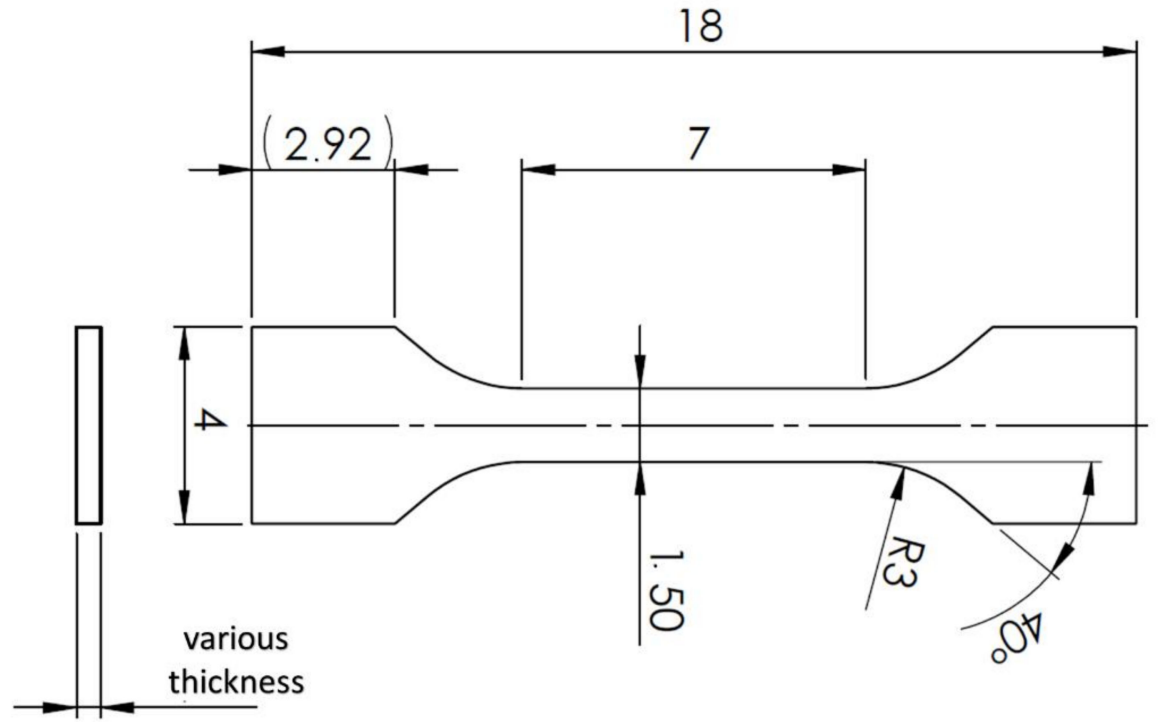

Figure 2. Detailed geometry of flat tensile test specimens (dimensions in $\mathrm{mm}$ ).

EBM specimens were produced using the Arcam Q10 machine (software-materialise magics 20.0 version, Materialise, Leuven, Belgium) with $50 \mu \mathrm{m}$ thick layers under helium atmosphere and under pressure of about $4 \times 10^{-3}$ mbar. The chemical composition and particle size distribution of the Ti-6Al-4V ELI Arcam powder is provided in Tables 1 and 2, respectively. Prior to the actual electron beam melting, the powder bed was preheated to $1013 \mathrm{~K}$ by fast scanning with a defocused electron beam. Subsequent scanning of the focused electron beam was carried out with the following parameters: $4530 \mathrm{~mm} / \mathrm{s}$ scan speed, $15 \mathrm{~mA}$ current, $60 \mathrm{kV}$ voltage, and $200 \mu \mathrm{m}$ hatch spacing. The thickness of contour was fixed. Specimen designations, dimensions, and orientations for the EBM-processed samples are provided in Table 3 and Figure 1. 
Table 1. Chemical composition of EBM powders according to the specifications of powder producers.

\begin{tabular}{ccccccccc}
\hline \multirow{2}{*}{ AM Technology } & \multicolumn{10}{c}{ Weight (\%) } \\
\cline { 2 - 10 } & Ti & Al & V & $\mathbf{C}$ & Fe & O & N & H \\
\hline EBM & Balance & 6.49 & 4.01 & 0.02 & 0.18 & 0.07 & 0.02 & 0.001 \\
\hline
\end{tabular}

Table 2. EBM Powder size distribution provided by powder producers.

\begin{tabular}{cccc}
\hline \multirow{2}{*}{ AM Technology } & \multicolumn{3}{c}{ Powder Size $(\mu \mathrm{m})$} \\
\cline { 2 - 4 } & D10 & D50 & D90 \\
\hline EBM & 55 & 76 & 106 \\
\hline
\end{tabular}

Table 3. Specimen data set designation and build orientations for EBM specimens.

\begin{tabular}{|c|c|c|c|c|}
\hline Data Set & Original Diameter (mm) & $\begin{array}{c}\text { Original } \\
\text { Thickness (mm) }\end{array}$ & $\begin{array}{l}\text { As-Deposited Cross } \\
\text { Section Area }\left(\mathrm{mm}^{2}\right)\end{array}$ & Orientation \\
\hline 1 & - & 0.5 & 0.75 & ZXY \\
\hline 2 & - & 1.0 & 1.50 & ZXY \\
\hline 3 & - & 1.5 & 2.25 & ZXY \\
\hline 4 & - & 2.0 & 3.00 & $\mathrm{ZXY}$ \\
\hline 5 & - & 2.5 & 3.75 & ZXY \\
\hline 6 & - & 3.0 & 4.50 & ZXY \\
\hline 7 & - & 1.0 & 1.50 & $\mathrm{XYZ}$ \\
\hline 8 & - & 1.5 & 2.25 & $X Y Z$ \\
\hline 9 & - & 2.0 & 3.00 & $\mathrm{XYZ}$ \\
\hline 10 & - & 0.5 & 0.75 & $X Z Y$ \\
\hline 11 & - & 1.0 & 1.50 & $X Z Y$ \\
\hline 12 & - & 1.5 & 2.25 & $X Z Y$ \\
\hline 13 & 0.5 & - & 0.79 & ZXY \\
\hline 14 & 1.0 & - & 1.77 & ZXY \\
\hline 15 & 1.5 & - & 3.14 & ZXY \\
\hline 16 & 2.0 & - & 4.91 & ZXY \\
\hline 17 & 2.5 & - & 7.07 & ZXY \\
\hline 18 & 3.0 & - & 9.62 & ZXY \\
\hline 19 & 6.0 & - & 28.26 & ZXY \\
\hline
\end{tabular}

Previously published work on SLM-processed specimens utilized an Ar atmosphere with the M2 Concept Laser machine without any bed preheating, additional details provided elsewhere [13]. In particular, to minimize residual stresses after the SLM process, the samples were annealed under vacuum by first slow heating to $1093 \mathrm{~K}$ over $4 \mathrm{~h}$, then holding for $1.5 \mathrm{~h}$ at $1093 \mathrm{~K}$ and then slow cooling to $773 \mathrm{~K}$, followed by furnace cooling to room temperature [13].

The mechanically tested samples denoted as-deposited represent samples tested without machining while those designated as machined were ground to final dimensions. Surface grinding of the flat specimens was carried out on metallographic grinding machines using water-cooling from all sides. The machined round specimens were first turned on a lathe and then finish-machined to the same surface roughness as the flat samples. This stress relief temperature was somewhat higher than typically used (e.g., $873 \mathrm{~K}$ ) to ensure relaxation of residual stresses and further decomposition of the as-deposited martensitic microstructure. 
In addition to the flat and round samples, miniature flat specimens (M-TT [9,10], Figure 3) were excised from the $6 \mathrm{~mm}$ diameter round ZXY specimens, as shown in Figure 4.
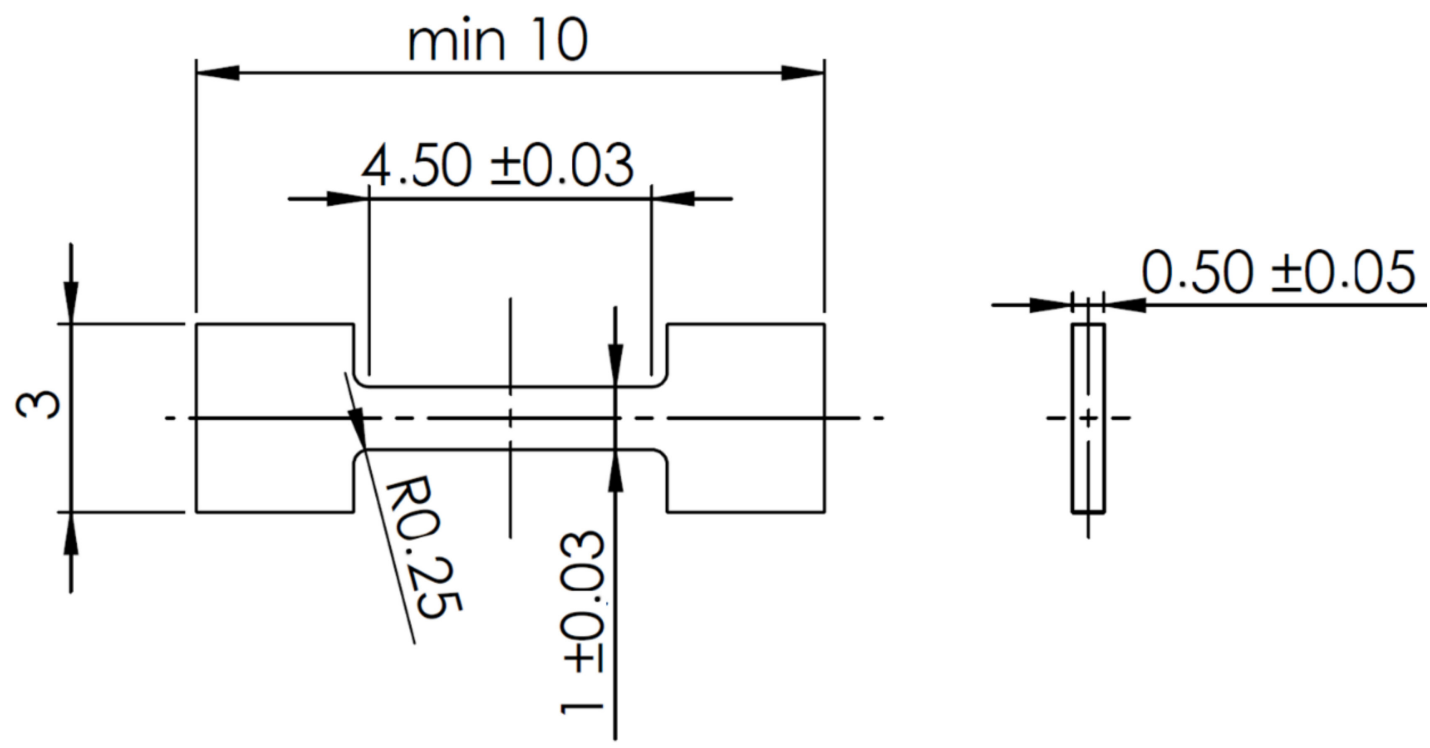

Figure 3. Geometry of M-TT flat tensile test specimens (dimensions in $\mathrm{mm}$ ) excised from the $6 \mathrm{~mm}$ diameter round sample shown in Figure 4.

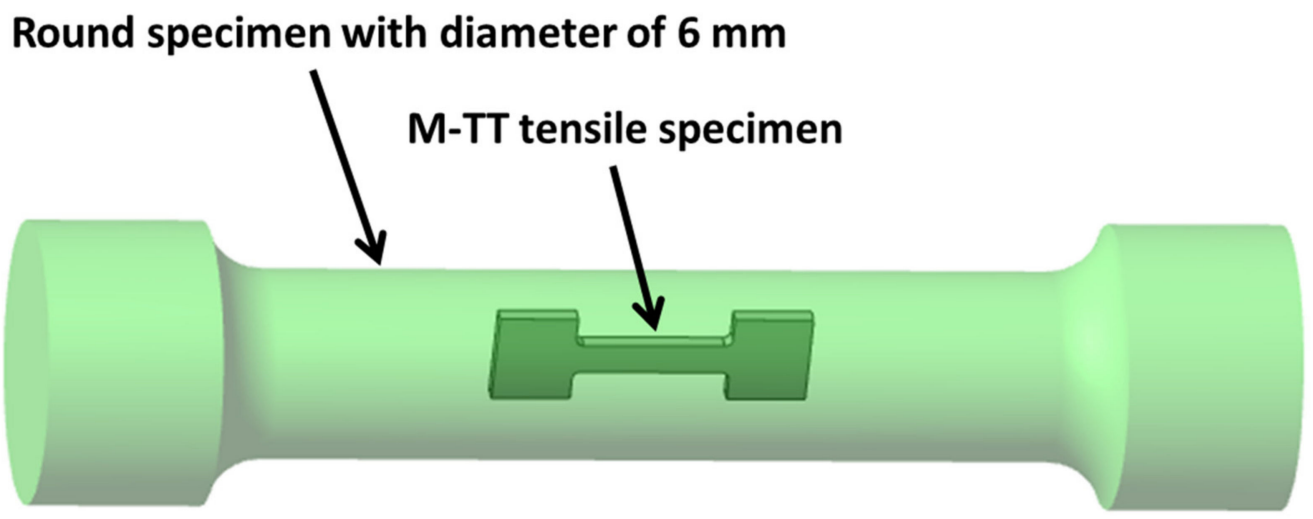

Figure 4. Schematic illustration of M-TT flat sample excised from the $6 \mathrm{~mm}$ diameter round sample.

\subsection{Tensile Testing}

The tensile tests were carried out under quasi-static loading conditions at a strain rate of $0.001 \mathrm{~s}^{-1}$ at room temperature using a $5 \mathrm{kN}$ capacity linear drive testing machine (LabControl s.r.o., Opava, Czech Republic) designed for the small size specimens. The deformation was measured using an optical extensometer based on the Digital Image Correlation technique following the ASTM E8 standard. Before tensile testing, the dimensions of each specimen were carefully measured by a digital micrometer and after testing by a stereomicroscope. Additional details of this test technique are described elsewhere [13]. The $0.2 \%$ offset yield stress (OYS) and ultimate tensile stress (UTS) were determined and engineering stress-strain (i.e., extensometer strain) curves were constructed. Average values reported for the various tensile properties were always calculated from at least three valid measurements.

\subsection{Statistical Analysis}

Shapiro-Wilk tests indicated non-normally distributed data, so the nonparametric Wilcoxon test was used for data analysis. Spearman rank correlation coefficients were calculated to evaluate 
correlations between the mechanical parameters and the cross-sectional area of the samples. Significance was set at $p<0.05$.

\subsection{Fracture Surface and Microstructure Evaluations}

The fracture surfaces of the broken tensile test samples were examined with a TESCAN VEGA-3 LMU scanning electron microscope (TESCAN VEGA-3 LMU, Brno, Czech Republic). Microstructure characterization was performed using with an OLYMPUS PME3 optical light microscope (Olympus PME3, Tokyo, Japan) and SEM. The metallographic samples were prepared parallel to the build direction (i.e., cut across deposited layers) by grinding with SiC papers, polishing with diamond paste, and final polishing with a silica suspension supplemented with 20 vol.\% of $\mathrm{H}_{2} \mathrm{O}_{2}$. Porosity was evaluated using image analysis with ImageJ software (ImageJ software, version 1.51, NIH, Bethesda, MD, USA) on unetched samples taken from longitudinal sections of a whole sample. The polished metallographic samples were then etched with Kroll's reagent and the microstructures were documented and quantified by both OM and SEM using the ImageJ software.

\section{Results}

\subsection{Tensile Properties}

Examples of stress-strain curves obtained from three measurements of the as-deposited flat samples with thickness of $1 \mathrm{~mm}$ and orientation ZXY are depicted in Figure 5 for the EBM-processed samples. The stress-strain curves for multiple samples show a clearly defined shape and good repeatability.

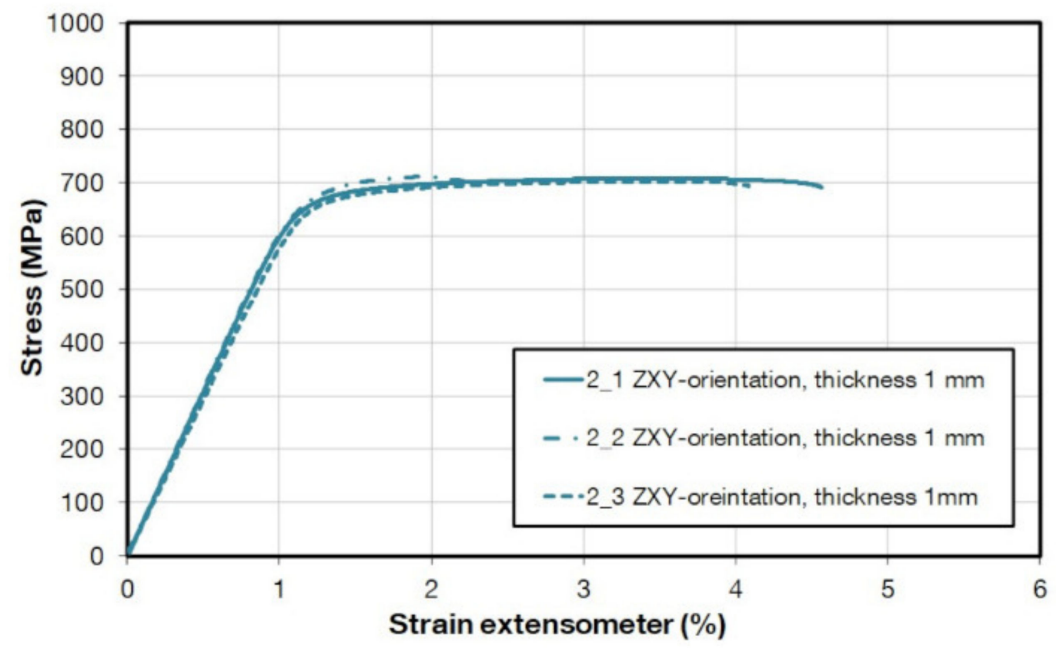

Figure 5. Engineering stress-strain curves of the as-deposited EBM-processed sample set with thickness of $1 \mathrm{~mm}$.

Figure 6 summarizes the average values of mechanical properties for the EBM-processed flat and round specimens (as-deposited surfaces and machined) and clearly shows the effects of machining on subsequent mechanical properties. In addition, the $95 \%$ confidence interval bands of the results are provided in Figure 6a,b.

The results for the as-deposited flat EBM samples show that both OYS and UTS values increased with increasing sample thickness $(p<0.001, \mathrm{r}=0.79)$, although this effect was not significant for the EBM-processed machined flat samples ( $p=0.30, \mathrm{r}=0.17)$.

The trends observed for the flat samples summarized in Figure 6 are compared to the results obtained on the round samples. Strength values for the round samples also increased with increasing sample thickness for as-deposited $(p<0.001, \mathrm{r}=0.63)$ and machined samples $(p=0.002, \mathrm{r}=0.78)$. The machined round specimens exhibited higher strength values (Wilcoxon test $p<0.001$ for UTS and 
OYS) while the mean difference in UTS between machined and as-deposited specimens is around $76 \mathrm{MPa}$.

(a)

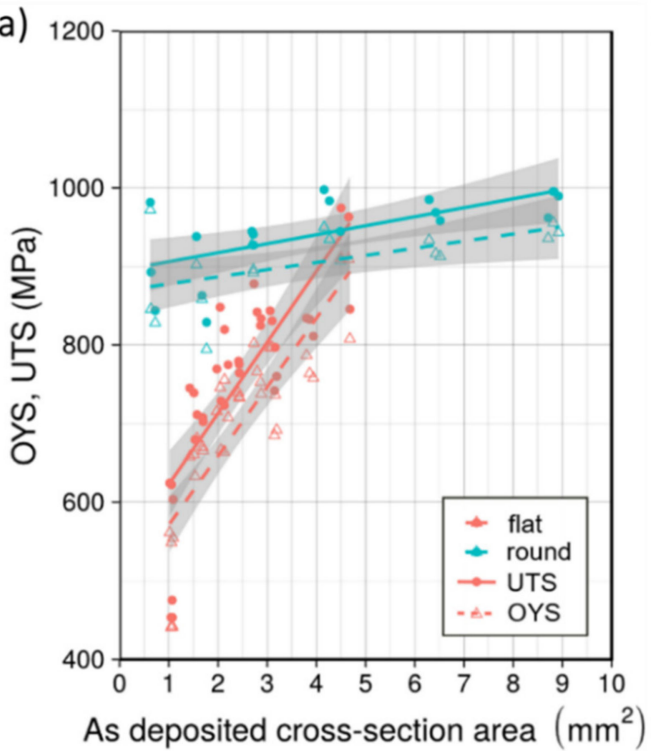

(b)

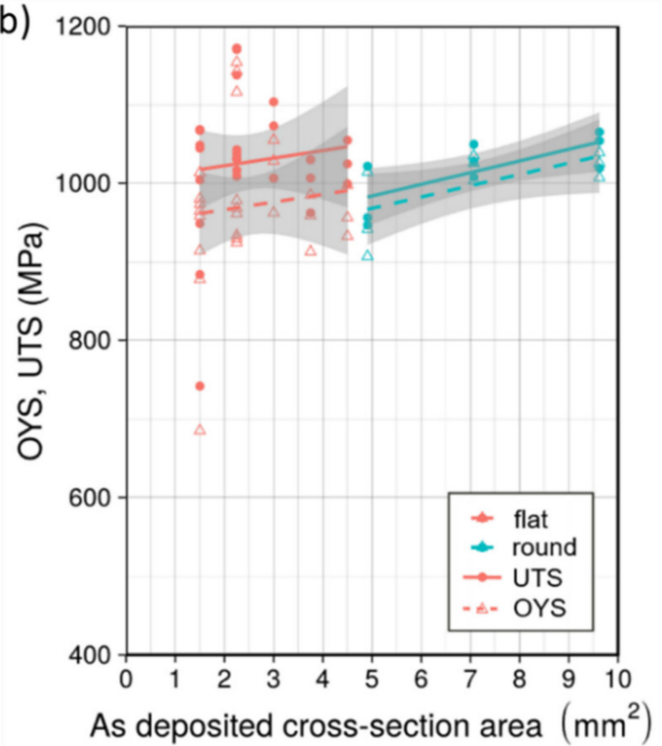

Figure 6. Average value of OYS and UTS with standard deviation for: (a) as-deposited EBM-processed flat and round specimens; (b) machined EBM-processed flat and round specimens.

Figure 7 summarizes the average values for mechanical properties for the SLM-processed flat and round specimens from previous work [13] and is provided to enable eventual comparison to the EBM-processed materials. The average strength values for the machined SLM specimens were not dependent on the sample thickness $(r=0.003, p=0.994$ and $r=0.054, p=0.676$ for OYS and UTS, respectively). The $95 \%$ confidence intervals of the obtained results are also shown in Figure 7a,b.

(a)

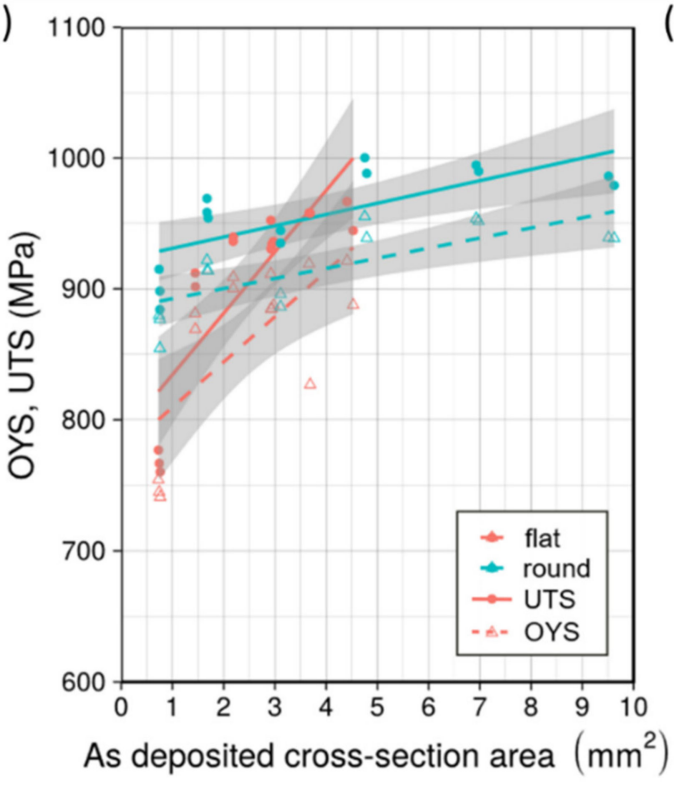

(b)

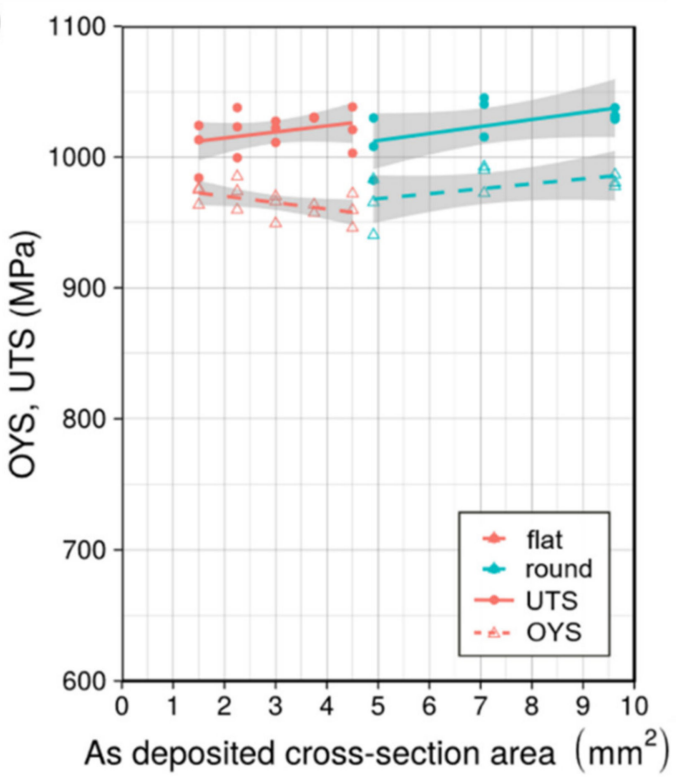

Figure 7. Average values for OYS and UTS with standard deviations for: (a) as-deposited SLM flat and round specimens, (b) machined SLM flat and round specimens.

The values of tensile properties for the SLM-processed samples appear to stabilize with as-deposited specimen cross sections greater than $3.0 \mathrm{~mm}^{2}$ (i.e., diameter $>2 \mathrm{~mm}$ ). Between the as-deposited and the machined round specimens a significant difference of strength (e.g., around 
$50 \mathrm{MPa}$ ) was observed (Wilcoxon test $p<0.001$ for UTS and OYS). The machined round SLM specimens show no thickness dependence for the strength parameters $(\mathrm{r}=-0.48, p=0.12$ and $\mathrm{r}=-0.48, p=0.11$ for OYS and UTS, respectively). However, much less scatter is evident for the SLM-processed flat and round specimens in comparison to the EBM-processed samples.

\subsection{Build Orientation Effects for EBM Samples}

Figure 8 provides box and whisker plots to summarize the effects of build orientation on EBM-processed samples. A relatively small difference in strength values (e.g., <10 MPa) was exhibited by EBM-processed samples with different build orientations, Figure $8 \mathrm{a}, \mathrm{b}$ with larger differences evident for samples with as-deposited surfaces. Build orientation effects for the SLM-processed samples are also shown in Figure 8a,b and have been discussed elsewhere [13].
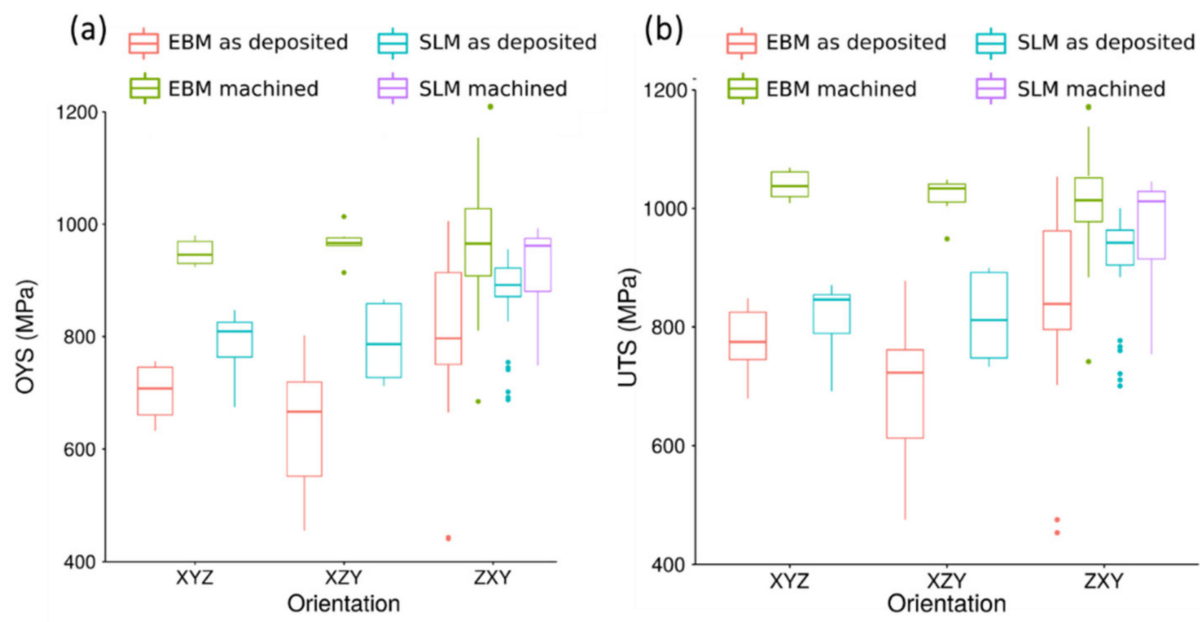

Figure 8. Comparison of average values for as-deposited and machined EBM specimens with different build orientations: (a) OYS, (b) UTS. Data for SLM flat specimens from previous work is provided for comparison.

\subsection{Results for Miniature M-TT Specimens}

Table 4 shows that the mechanical properties for the $6 \mathrm{~mm}$ diameter round specimens and the excised miniature specimens are in good agreement. The miniature M-TT specimen method produces slightly higher data scatter for EBM-processed and excised samples, but still only 2-3\% compared to about $1 \%$ for the SLM-processed samples [13], and typically $<1 \%$ for the $6 \mathrm{~mm}$ diameter round samples.

Table 4. Comparison of results for the $6 \mathrm{~mm}$ diameter round specimens and the excised miniature M-TT specimens. SLM data provided from previous work.

\begin{tabular}{|c|c|c|c|c|c|}
\hline \multirow{2}{*}{ Method } & \multirow{2}{*}{ Data Set } & \multirow{2}{*}{$\begin{array}{l}\text { As-Deposited Cross } \\
\text { Section Area }\left(\mathrm{mm}^{2}\right)\end{array}$} & \multirow{2}{*}{ Value } & OYS & UTS \\
\hline & & & & (MPa) & (MPa) \\
\hline \multirow{4}{*}{ EBM } & \multirow{2}{*}{ M-TT reduced section } & \multirow{2}{*}{0.50} & Average & 1034.2 & 1104.3 \\
\hline & & & Standard deviation & 19.8 & 35.5 \\
\hline & \multirow{2}{*}{$6 \mathrm{ZXY}$} & \multirow{2}{*}{22.89} & Average & 1052.9 & 1093.8 \\
\hline & & & Standard deviation & 2.6 & 4.7 \\
\hline \multirow{4}{*}{ SLM } & \multirow{2}{*}{ M-TT reduced section } & \multirow{2}{*}{0.50} & Average & 988.0 & 1038.7 \\
\hline & & & Standard deviation & 10.4 & 9.9 \\
\hline & \multirow{2}{*}{$6 \mathrm{ZXY}$} & \multirow{2}{*}{22.89} & Average & 976.3 & 1025.0 \\
\hline & & & Standard deviation & 12.0 & 3.8 \\
\hline
\end{tabular}




\subsection{Microstructure and Fractography}

Figures 9 and 10 show the microstructure at various magnifications for the as-deposited EBM and post-processed SLM samples [13], respectively. For both processes, the microstructure consists of columnar prior- $\beta$ grains that grew parallel to the build direction across many deposited layers (Figure 9a,c and Figure 10a,c). The higher-magnification images (Figure 9b,d) and Figure 10b,d) show the lamellar $\alpha+\beta$ morphology within the prior- $\beta$ grains. This $\alpha+\beta$ microstructure is formed directly during the slower cooling rate present in the EBM process, since every layer is first preheated by a prescan at a lower power that sets the powder-bed temperature to a desired value (i.e., $1013 \mathrm{~K}$ ). Because the material was kept above the martensitic transformation temperature $(\mathrm{Ms}=848 \mathrm{~K}$ [22]), transformation of the $\beta$ phase into the $\alpha+\beta$ phase mixture occurs instead of the martensitic transformation [23]. In the case of SLM-processed specimens [13], the lack of bed preheat produces much higher cooling rates and a martensitic microstructure in the as-deposited SLM Ti-6Al-4V as shown by many others [13]. The two-phase microstructure shown in Figure 10 is the result of the post-process heat treatment that enables the as-deposited martensitic microstructure to transform to a more stable $\alpha+\beta$ phase mixture during annealing at $1093 \mathrm{~K}$. Figures 9 and 10 also show that the post-processed SLM $\alpha+\beta$ microstructure is coarser than that of the as-deposited EBM, consistent with the somewhat lower strengths exhibited by the SLM post-processed samples.
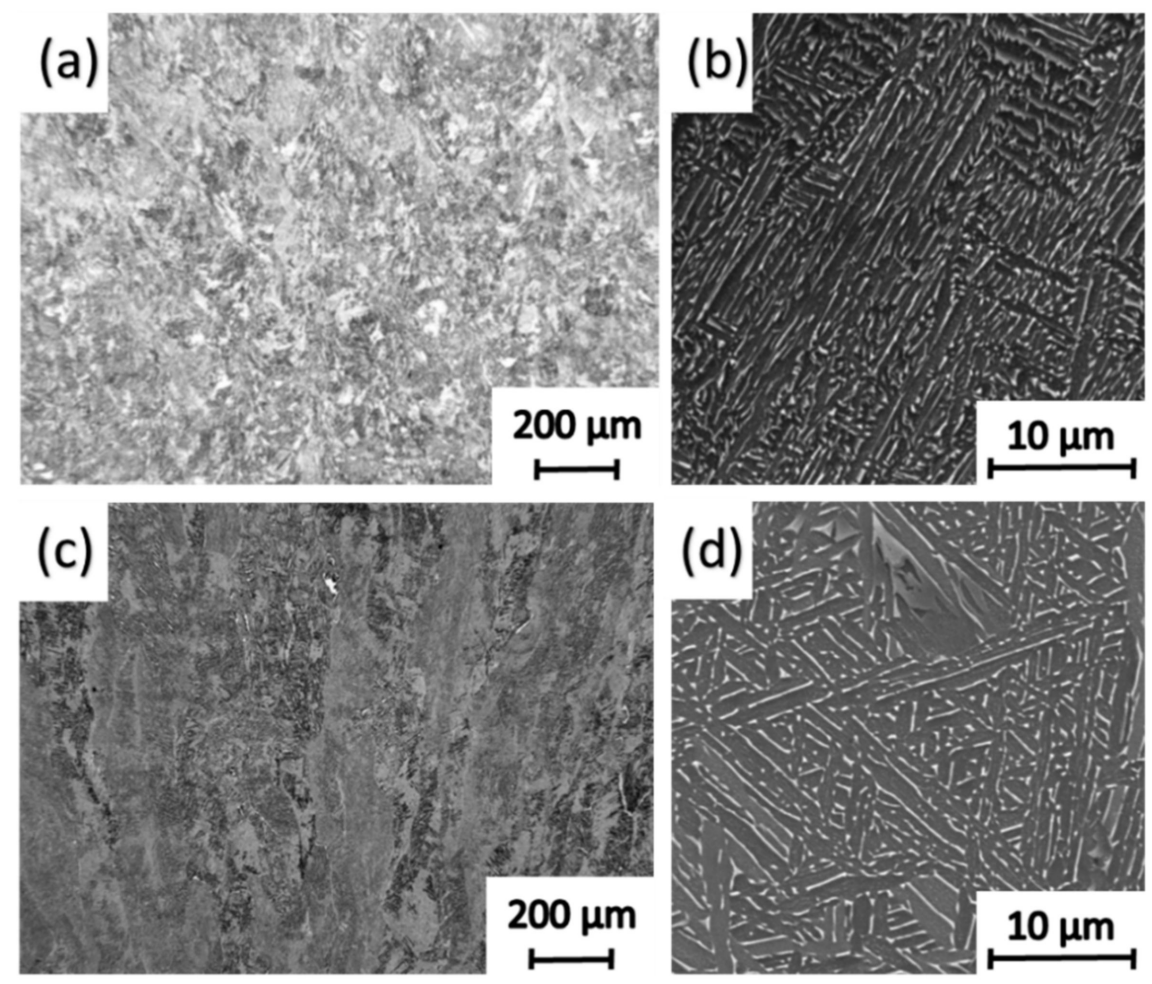

Figure 9. Microstructure of the flat EBM-processed specimens built in the ZXY orientation: (a) thickness of $1 \mathrm{~mm}$, (b) detail of specimen with thickness 1 of $\mathrm{mm}$, (c) thickness of $3 \mathrm{~mm}$ and (d) detail of specimen with thickness of $3 \mathrm{~mm}$.

Differences between the SLM- and EBM-processed microstructures, including porosity, were quantified and are summarized in Table 5. The dependence of porosity on sample deposition thickness showed no clear trend for both SLM- and EBM-processed specimens (Table 5), suggesting that the specimen thicknesses investigated probably do not significantly influence the quality of melting. However, some differences in microstructure fineness/scale (e.g., $\alpha$-lamellae thickness and width of prior- $\beta$ grains) with respect to specimen thickness are evident as summarized in Figure 11. 
Table 5. Image analysis results-porosity, thickness of $\alpha$ lamellae, and width of prior- $\beta$ grains. Data for SLM-processed material included from previous work.

\begin{tabular}{ccccc}
\hline \multirow{2}{*}{ Method } & $\begin{array}{c}\text { As-Deposited Cross } \\
\text { Section Area }\left(\mathbf{m m}^{2}\right)\end{array}$ & Average Porosity (\%) & $\begin{array}{c}\text { Thickness of } \\
\text { Lamellae } \boldsymbol{\alpha}(\boldsymbol{\mu m})\end{array}$ & $\begin{array}{c}\text { Width of Prior- } \beta \\
\text { Grains }(\boldsymbol{\mu m})\end{array}$ \\
\cline { 2 - 5 } & 0.75 & 0.38 & $1.07 \pm 0.43$ & $124.5 \pm 22.5$ \\
\cline { 2 - 5 } SLM & 1.50 & 0.14 & $1.19 \pm 0.40$ & $104.3 \pm 26.8$ \\
\cline { 2 - 5 } & 2.25 & 0.10 & $1.36 \pm 0.49$ & $109.1 \pm 18.2$ \\
\hline \multirow{3}{*}{ EBM } & 4.50 & 0.30 & $1.29 \pm 0.46$ & $87.7 \pm 20.9$ \\
\cline { 2 - 5 } & 0.75 & 0.07 & $0.43 \pm 0.15$ & - \\
\cline { 2 - 5 } & 1.50 & 0.05 & $0.63 \pm 0.25$ & - \\
\hline
\end{tabular}
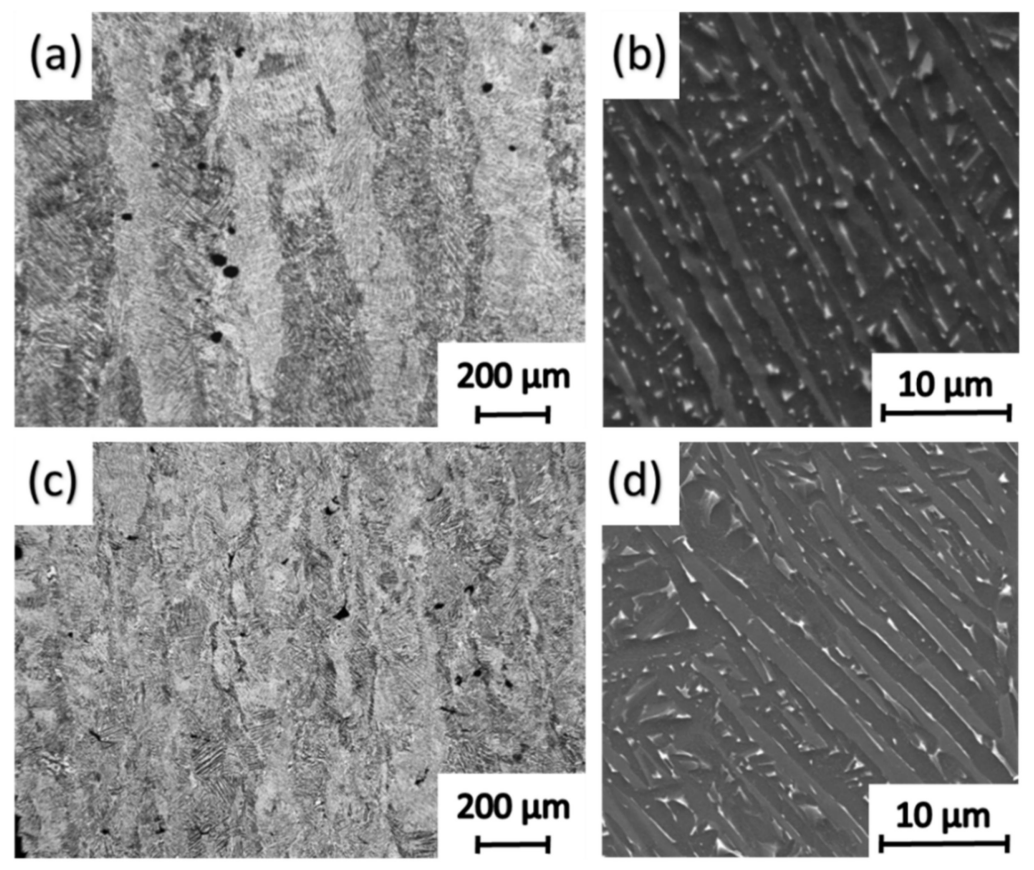

Figure 10. Microstructure of the stress relieved flat SLM-processed specimens built in the ZXY orientation: (a) thickness of $1 \mathrm{~mm}$, (b) detail of specimen with thickness of $1 \mathrm{~mm}$, (c) thickness of $3 \mathrm{~mm}$ and (d) detail of specimen with thickness of $3 \mathrm{~mm}$.

For the as-deposited EBM material, microstructure coarsening is exhibited, similar to that reported by Tan et al. [24], and is consistent with the higher heat accumulation that accompanies the larger volume of melted powder per layer with EBM. Higher melt temperatures and longer dwells promote growth of both the prior- $\beta$ grains and $\alpha$-lamellae, due to the slower cooling rates provided by the combination of preheated powder bed and higher power (i.e., bigger melt pool) associated with EBM. The partitioning ratios of aluminum and vanadium are also increased so that more aluminum partitions to the $\alpha$ phases and more vanadium partitions to the $\beta$ phase [24]. It was not possible to distinguish the prior- $\beta$ grains in the thinner EBM-processed samples, as the grains were irregular, inclined and harder to distinguish (Figure $9 a$ ), although the prior- $\beta$ columnar grains exhibited a more regular shape with regular orientation along the build direction with increasing sample thickness [17]. 


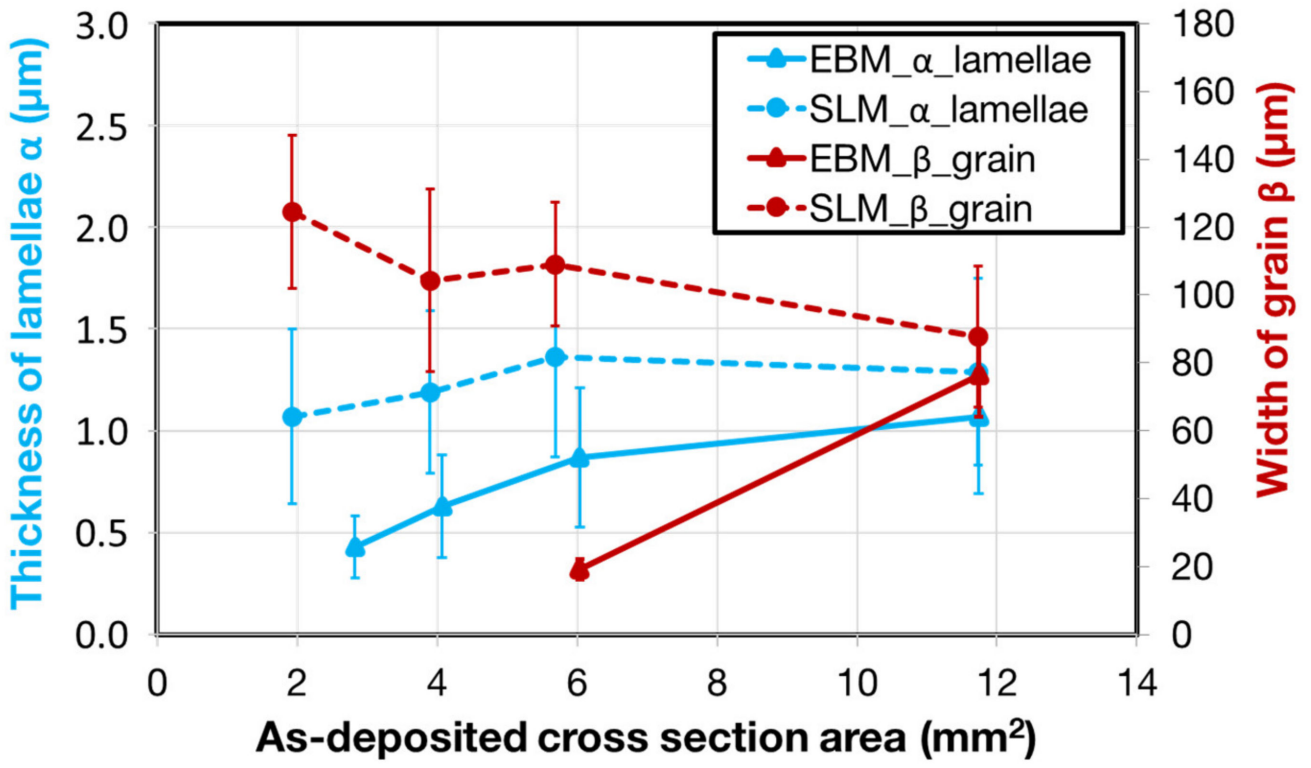

Figure 11. Summary of microstructure scale and its dependence on as-deposited cross section area. SLM data summarized from previous work.

For the post-processed SLM samples published elsewhere [13], the opposite trend was observed for the prior- $\beta$ grains and $\alpha$-lamellae. In the case of SLM-processed material, the lack of preheated powder bed affects the heat flow during cooling differently for different thickness samples. In this case, cooling occurs through the already solidified substrate and surroundings, but is always more rapid cooling compared to EBM. Thus, the cooling rate for SLM-processed material increases with increasing specimen thickness since the higher volume of the melted and solidified material transfers the heat away. Reducing the sample thickness for the SLM-processed samples reduces the cooling rate and promotes growth of the prior- $\beta$ grains. Therefore, in Figure 11 the prior- $\beta$ grain widths increase with decreasing sample thickness.

The contour layer was not identifiable in the longitudinal sections of any of the EBM or SLM samples, Figure 12. The microstructure at the fringe in the test area is similar to that exhibited in the interior, except for a thin layer of a few $\mu \mathrm{m}$ at the fringe of the unmachined samples. It can be assumed that all marginal zones that could influence the results have been removed by the post-processing-machining, i.e., no influence of the contour layer is to be expected.

Representative fracture surfaces for both EBM- and SLM-processed [13] samples are shown in Figure 13. Rougher external sample surfaces are evident for the EBM builds due to the larger powder sizes compared to the SLM builds Fracture was always of a ductile trans-granular nature, including the M-TT samples. However, the fracture surfaces of the SLM-processed samples [13] exhibited more defects in comparison to EBM-processed specimens that utilized a preheated powder bed. The defects in the SLM-processed samples included small gas pores, larger spherical voids likely due to key-hole effects and lack of fusion. The spherical pores were mainly found in the SLM-processed samples with smaller cross-sections, apparently due to greater heat accumulation and lower heat dissipation. In such cases, the melt pool could destabilize and collapse, leaving a spherical void with entrapped metal vapor in the solidified material. On the other hand, lack of fusion defects were more abundant in SLM-processed samples [13] with larger cross-sections. In these cases, the higher heat dissipation and resulting faster solidification promoted inadequate fusion between successively melted tracks in one layer for the Power (P)-Velocity (V) combinations used in that work. 

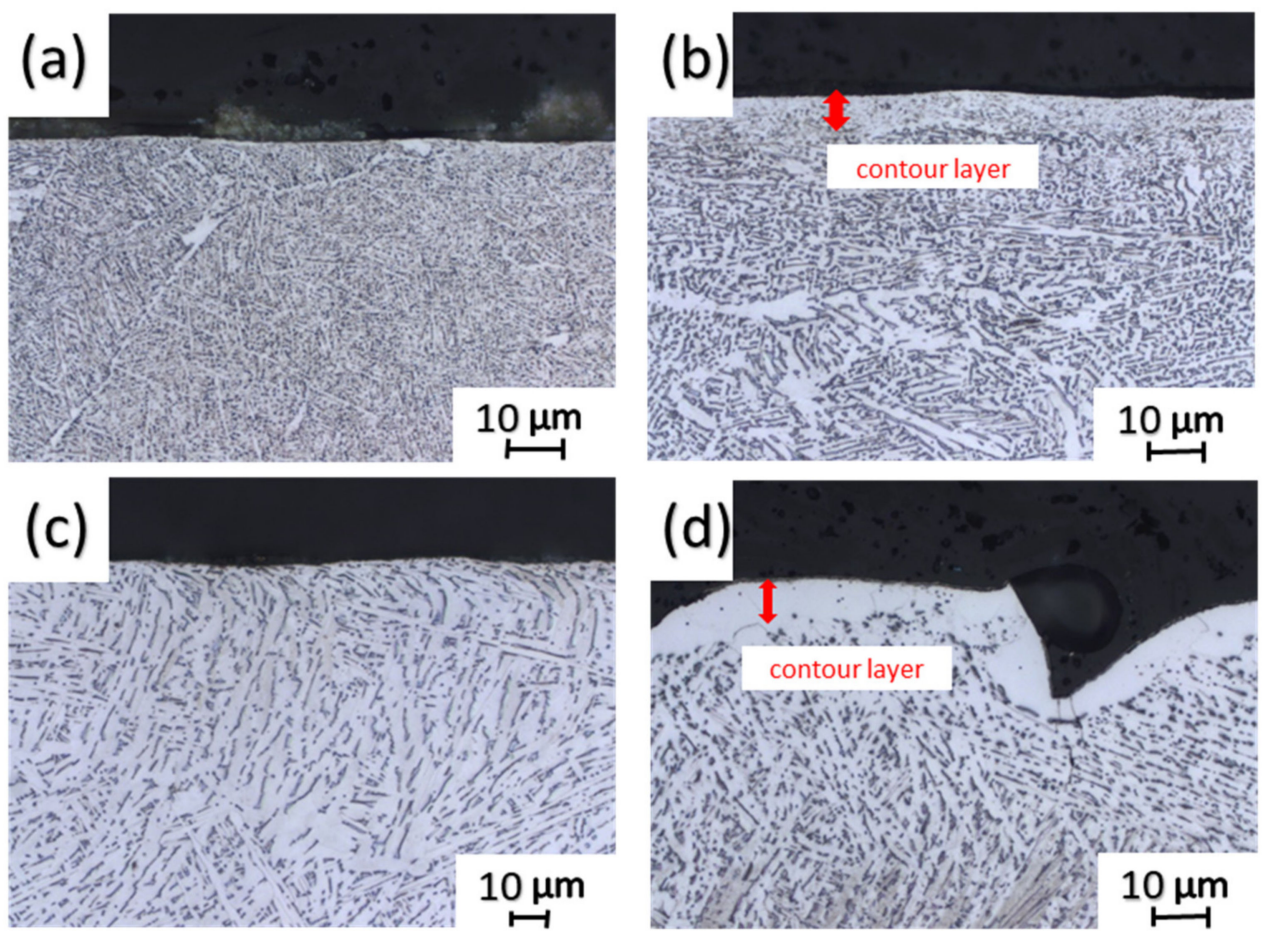

Figure 12. Surface of the samples in longitudinal direction: (a) EBM machined, flat sample in ZXY direction, (b) EBM as-deposited, flat sample in ZXY direction, (c) SLM machined, flat sample in ZXY direction and (d) SLM as-deposited, flat sample in ZXY direction.
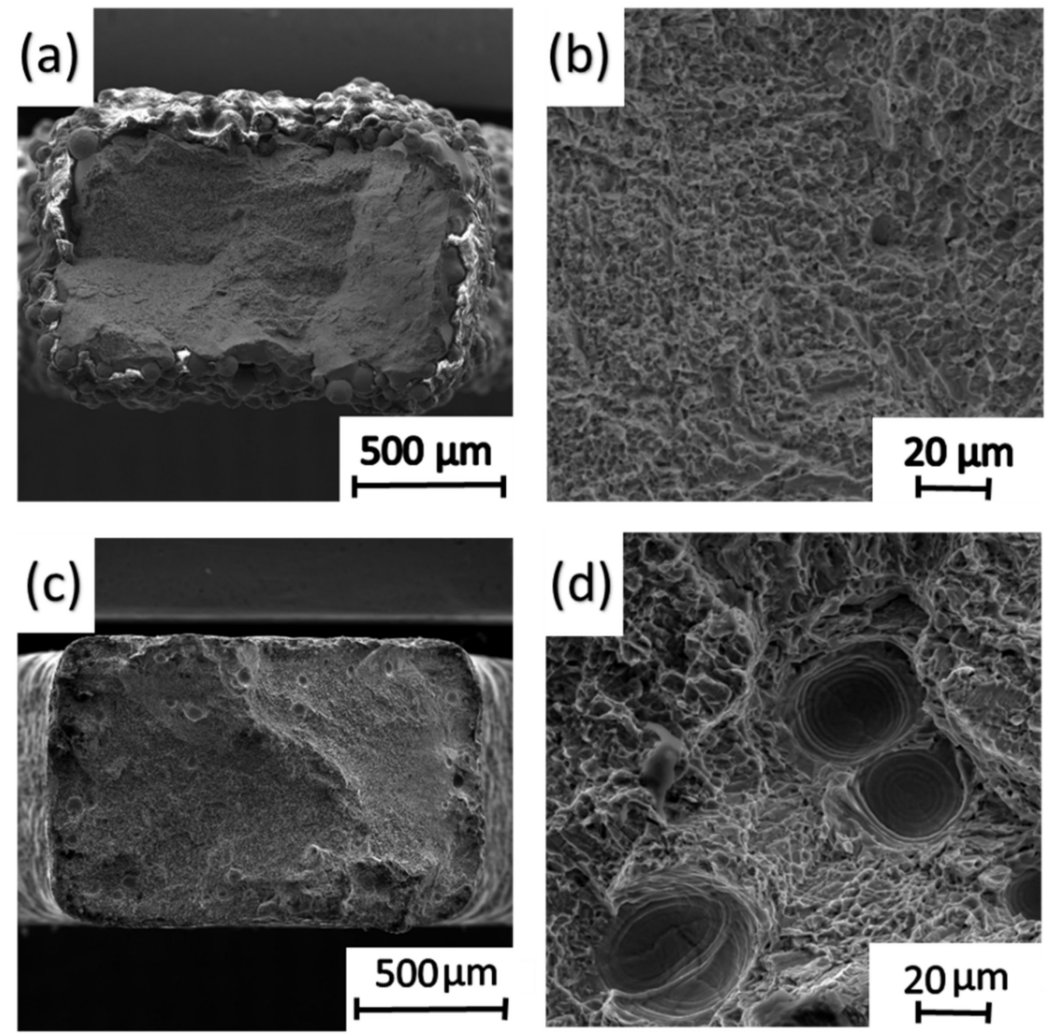

Figure 13. Fracture surfaces of ZXY specimens with $1 \mathrm{~mm}$ thickness: (a) produced by EBM, (b) detail of fracture in EBM sample, (c) produced by SLM and (d) detail of fracture in SLM sample. 


\section{Discussion}

\subsection{Sample Thickness}

This research captures aspects of the effects of specimen thickness, sample machining, build orientation, and specimen shape on mechanical properties of EBM-additively manufactured Ti-6Al-4V, with comparison to previously published work on SLM-processed material by the same authors [13]. The purpose is to provide a complete study that covers all of the above-mentioned influences. In order to capture these effects completely, original data are included that complements the results from our previous study [13]. Specimens of the same thickness as reported in [13] were produced in the present work to demonstrate the consistency in data from both testing series in addition to producing additional samples with other thicknesses. The graphs in Figures 14 and 15 compare the results of the previous study [13], designated " 1 ", to the present batch (i.e., designated "2"). Good agreement of the previous (first batch "1" [13]) and present (second batch '2') flat specimen series, for both SLM and EBM methods are evident. However, the strength data from the second batch are slightly higher for SLM samples [13] and a bit lower for EBM samples. The higher values for SLM-processed samples are related to the fact that a new supplier of the titanium powder was used. The small difference between different batches of the EBM samples is partly caused by the high surface roughness of the EBM specimens which affects the accurate measurement of specimen dimensions.

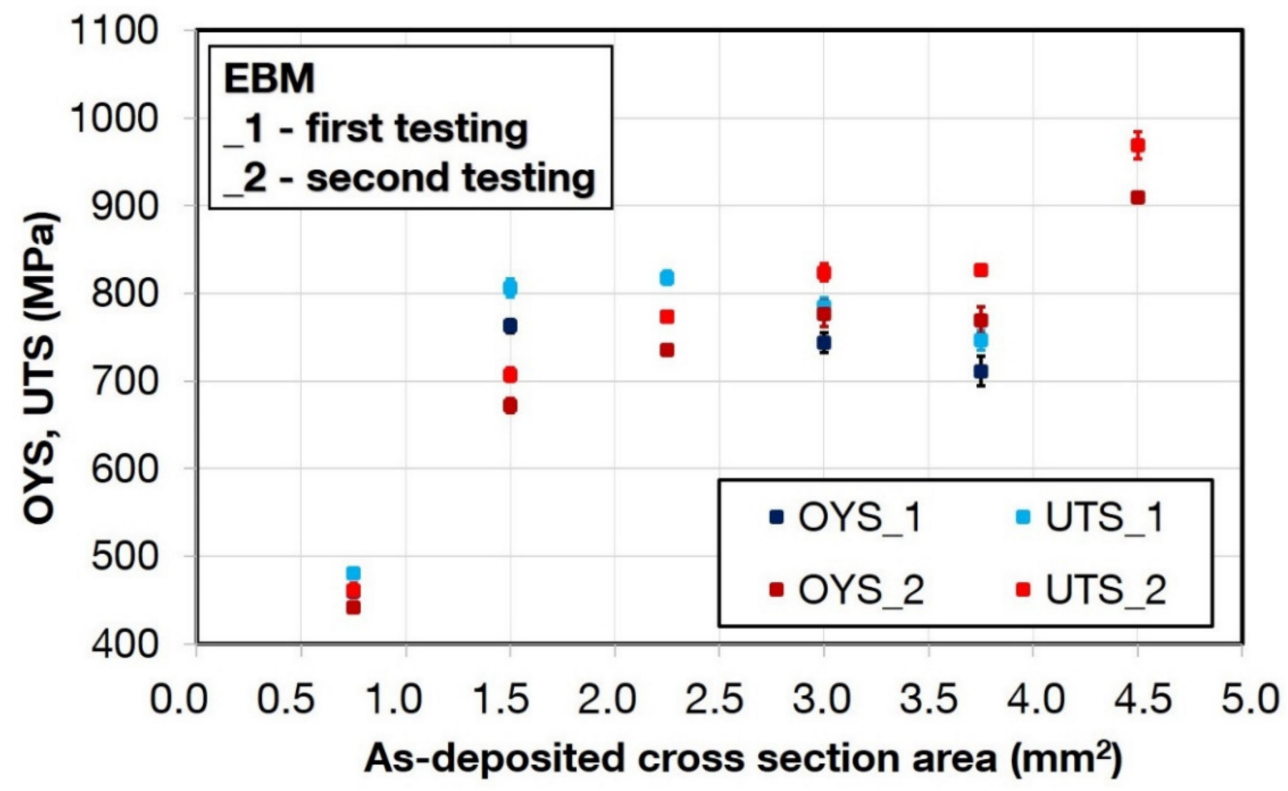

Figure 14. Average strength values obtained from the first (" 1 ") and the second ("2") batch of testing EBM-processed samples.

As shown previously, the dimensional measurements are more difficult and less accurate for as-deposited samples than machined samples. Because of this, the evaluation of Young's modulus was not conducted and values are not included presently. Metallography and fractography helped to clarify the observed differences between SLM- and EBM-processed materials. There have been several studies focusing on the influence of defects (e.g., especially porosity) on various mechanical properties [2,6,25-31]. Generally, it is difficult to evaluate the effect of sample thickness on sample elongation, because elongation is highly dependent on the presence of internal defects as well as the sample gage length. Because of this, the influence of size effect on the elongation and reduction of area values were not considered and are not further discussed. 


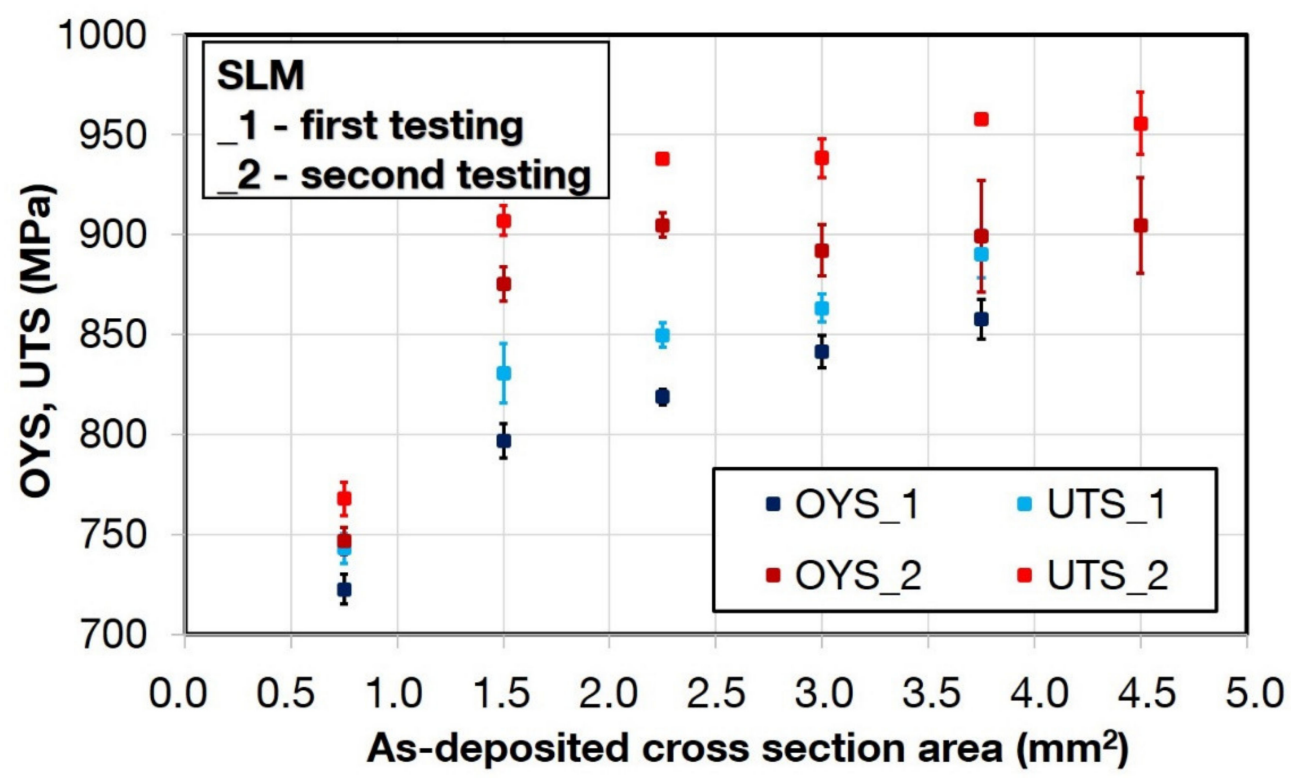

Figure 15. Average strength values obtained from the first (" 1 ") and the second (" 2 ") batch of testing SLM-processed samples.

Figures 16 and 17 shows the generally expected behavior of increasing strength that accompanies greater sample thickness, while the graphs further show the dependence of strength values on specimen surface length to cross-section ratio, as done previously [13]. The reproducibility and reliability of mini-tensile testing for both methods is again demonstrated. In addition, the present work reveals the potential of samples with as-deposited cross sections greater than $3.0 \mathrm{~mm}^{2}$ (i.e., $>2 \mathrm{~mm}$ diameter) and greater thickness to provide information about the quality of SLM-printed material, similar to conclusions reached previously [13].

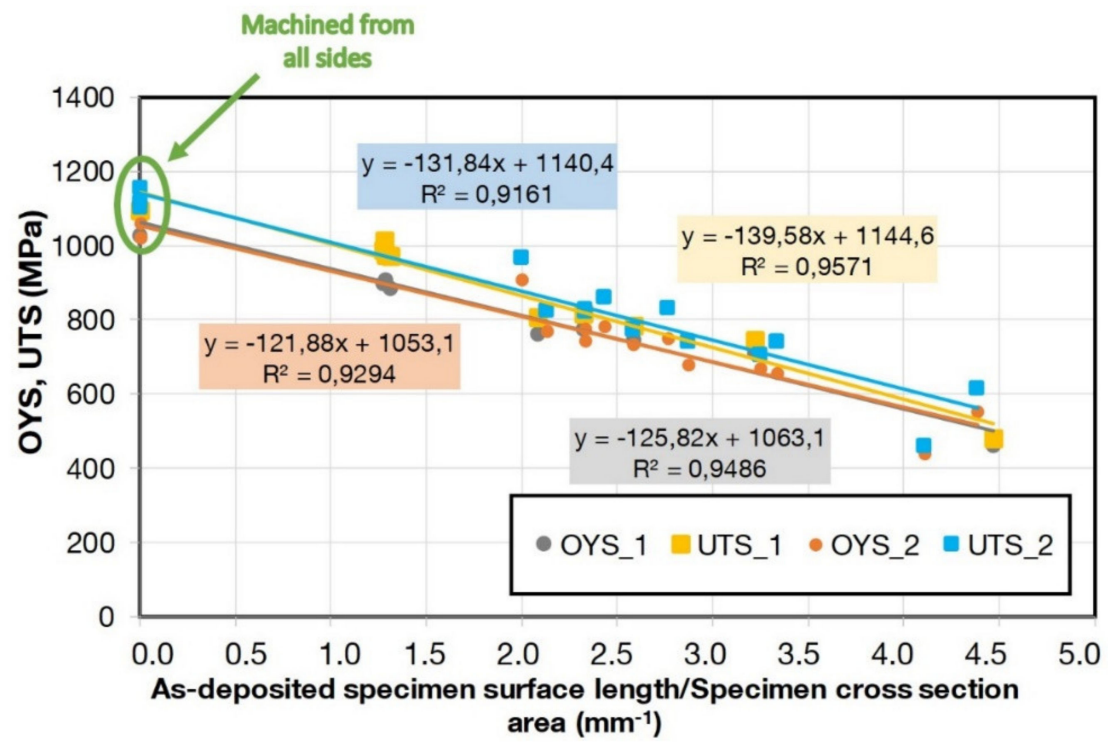

Figure 16. Dependence of OYS and UTS values on specimen surface length/cross section ratio for EBM-processed flat specimens from the first (" 1 ") and second ("2") batch of testing.

Figure 17 shows that the results from the first [13] and second batch of SLM-processed samples are dissimilar while the present results exhibited somewhat higher strength values. This discrepancy is partly related to the fact that a different supplier of the titanium powder was used for the second 
batch. Other work also showed that different powder suppliers produce different mechanical properties [32-34].

From the present results, and consistent with previous work [13], it is clear that the as-deposited surfaces strongly affect the tensile properties, although it appears that the surface effects on mechanical properties decreases with increasing specimen thickness since the tensile properties stabilized for samples with higher as-deposited thickness. Conversely, no significant influence of sample thickness on material strength was found for the machined samples; the results were comparable. Therefore, it can be stated that the build thickness itself should not influence/control the mechanical properties of components when the surface roughness is reduced when the surface is not responsible for fracture initiation. The microstructural differences between samples with different printed thicknesses are only slight and did not produce any significant macroscopic effects on mechanical properties. This is particularly evident for the post-processed SLM samples [13] since they all received the same stress relief heat treatment. However, mechanical properties showed a decreasing trend for the EBM-processed samples (Figure 7), related to the coarsening of the $\alpha$-lamellae (Figure 9). This coarsening was not present in the post-processed SLM specimens. The $\alpha / \beta$ interface is believed to play the primary role in strengthening 3D-printed Ti-6Al-4V as dislocations are always first emitted from $\alpha / \beta$ interfaces [24].

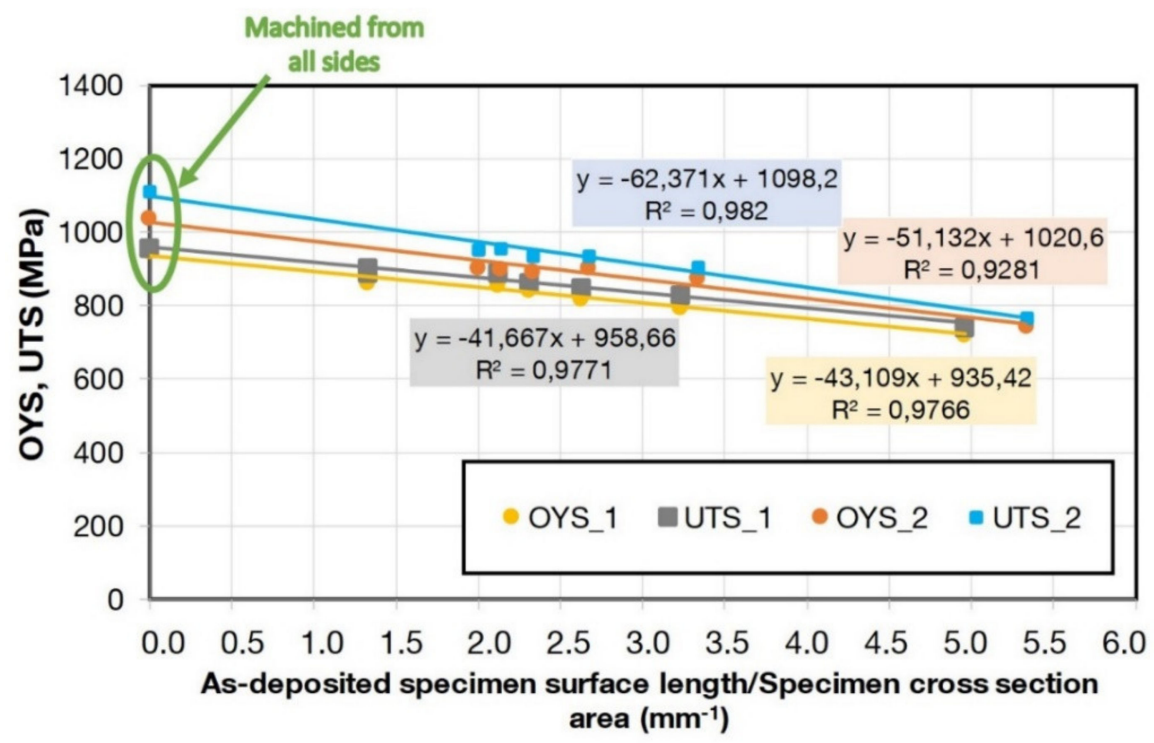

Figure 17. Dependence of OYS and UTS values on specimen surface length/cross section ratio for SLM-processed flat specimens the for first ("1") and second ("2") batch of testing.

\subsection{Build Orientation Effects}

For the purpose of describing the influence of build orientation for both deposition techniques, we extend the results from the first [13] and the second testing, as summarized in Figure 8. The influence of the build orientation is not possible to detect for EBM-processed specimens, Figure 8. The relatively high scatter in EBM strength results complicates the determination of any differences between specimens of different orientations. Moreover, the high surface roughness of EBM-deposited specimens appears to dominate the behavior, instead of being dominated by the influence of the microstructure and defects. The fracture surfaces of samples in the ZXY direction, along with their surface roughness, are shown in Figure 13a. In case of SLM-processed samples [13], the comparison among specimens with different build orientations (Figure 8) showed some differences in strengths values where the yield and ultimate strengths for ZXY-oriented SLM-processed samples were noticeably higher than that obtained for the other orientations. The source(s) of this behavior can be found in microstructure evaluation. In the SLM-processed samples, the effects of multiple melting in the ZXY direction during the process and the deposited parts have lower possibilities of heat conduction [13]. 


\subsection{Usability of M-TT Specimens}

The EBM M-TT specimens with thickness of $0.5 \mathrm{~mm}$ and width of $1 \mathrm{~mm}$ produced very similar values of strength (e.g., OYS $=1050 \mathrm{MPa}$, UTS $=1090 \mathrm{MPa}$ ) compared to the $6 \mathrm{~mm}$ diameter round samples. The SLM-processed samples similarly exhibited negligible differences in strength values between the M-TT and bulk samples [13], Table 4. However, significant amounts of defects on the fracture surface were evident, including lack of fusion defects. Lack of fusion defects, due to their high aspect ratio, can have a more significant impact on the mechanical behavior of the miniature samples in comparison to the larger specimens. The general agreement obtained between the miniature specimens and bulk round specimens continues to provide some confidence in using M-TT specimens for more efficient investigation of AM properties. However, the effects of sample thickness with respect to actual part dimensions/properties in critical locations must be carefully considered when choosing specific sample dimensions for evaluation of part-specific/location-specific properties.

\subsection{Microstructure}

Initial analyses of the microstructures suggested that the post-processing heat treatment applied to the SLM-processed samples [13] produced similar $\alpha+\beta$ microstructures for both the SLM and EBM samples. However, more detailed analyses consistently revealed a finer structure in the EBM-processed samples that is consistent with the details of the processing [24,25], as summarized next.

The first stage of microstructure formation is the same for both processes; Material is first melted by an energy source (i.e., either electron or laser beam) and solidifies rapidly as the energy source moves away from the melt pool. The very high thermal gradients between the melt and previously solidified material in the SLM-processed material, with cooling rates exceeding the critical rate of $410 \mathrm{~K} / \mathrm{s}$ for martensitic transformation [22], produce a predominantly martensitic microstructure within the prior- $\beta$ grains. The lack of preheating of the SLM powder bed enables retention of the martensitic microstructure in the as-built SLM-processed specimens [13]. In contrast, the EBM-processed samples were conducted in the presence of a powder bed preheated to near the beta-transus temperature. In addition, the higher energy of the electron beam (compared to the laser beam) provides more intense local heating of the melt, and consequently, a slower cooling rate. This promotes the formation of coarser prior- $\beta$ grains than typically found in as-deposited SLM-processed specimens. Gradual prior- $\beta$ grain coarsening can be observed with increasing number of layers in the thicker samples, along with a more regular shape and orientation along the build direction [35,36]. In contrast, it was not possible to distinguish the prior- $\beta$ grains, which were irregular and inclined to the build direction (Figure $9 a$ ) in the thinner samples.

In addition to the above, powder bed preheating in the EBM process also causes repeated phase transformations around the $\beta$-transus temperature $(1243 \pm 50 \mathrm{~K})$ producing a refining effect on the $\alpha$-lamellae. The elevated temperature of the EBM powder bed permits multiple transgressions above and below the $\beta$-transus temperature in previously solidified layers during the present and subsequent exposures to electron beam melting, in contrast to the thermal exposures experienced in the SLM-processed samples that do not use a preheated powder bed. In the case of SLM-processed samples [13], it was observed that the thickness of the $\alpha$-lamellae increased with increasing specimen thickness, similar to EBM-processed samples, while thicker SLM-processed specimens exhibited thinner prior- $\beta$ grains than identically processed thinner samples. One possible source of this relates to the material reheating that occurs due to the laser contour track. For the thinnest SLM-processed samples [13], the laser contour track occupies a greater fraction of the sample cross-section and the material in these areas are reheated twice with much more local heat accumulation compared to thicker SLM-processed samples. As a result, thicker prior- $\beta$ grains are initially formed, while the greater subsequent cooling rates associated with the higher local thermal gradients produces a finer martensitic structure in the SLM-processed material. Although the martensite needles transform to an $\alpha+\beta$ structure during post-process annealing, the thickness of the columnar prior- $\beta$ grains is not affected by annealing. Small differences are observed in the thickness of resulting $\alpha$-lamellae for SLM samples 
with different thickness [13]. These likely results due to the smaller amounts of reheating that occur in the samples with larger cross-sectional area. While such microstructural changes are reflected in the mechanical properties of the samples with machined surfaces, these effects are not very pronounced when the as-deposited (i.e., rough surface) samples are tested.

\subsection{Connection of Microstructure and Mechanical Properties}

The correlation of mechanical properties with microstructural features is complicated by the presence of rough surfaces in the as-deposited samples, as the present work shows that the as-deposited surfaces play a dominant role in the subsequent mechanical properties. For both EBM- and SLM-processed specimens [13], an increase in strength was exhibited with increasing specimen thickness (i.e., decreasing the surface perimeter to cross section ratio) as shown in Figures 16 and 17. However, removal of the as-deposited surface roughness via machining changed the trends and revealed the true effects of microstructural changes on the properties.

In the EBM-processed samples, removal of the rough as-deposited surfaces across the various thickness samples shows a more modest effect of thickness on strength (Figure 6b). The observed strength changes are now consistent with the microstructural coarsening experienced in the thicker EBM-processed samples where the thicknesses of both the $\alpha$-lamellae and prior- $\beta$ grains increased (Figure 11, Table 5). In contrast, for SLM-processed specimens [13], machining produced more uniform properties across all sample thicknesses, consistent with the similar microstructures produced via the post-processing heat treatment. In the SLM post-processed samples, the effects of increasing $\alpha$-lamellae thickness and decreasing thickness of prior- $\beta$ grains that occurs with increasing sample thickness (Figure 11, Table 5) produce little combined contribution to the mechanical properties.

\section{Conclusions}

In this study, the effects of changes in sample thickness on microstructure and mechanical properties of as-deposited and machined specimens of EBM-processed Ti-6Al-4V built in different orientations were investigated by testing more than fifty (50) miniature samples, and compared to previously published work [13] on a similar number of samples prepared by SLM techniques by the same authors. The following captures the key observations and conclusions:

- Mechanical properties of EBM-processed specimens are dependent on the as-deposited sample thickness. Differences in results obtained on the machined specimens is related to differences in the microstructures at the different thicknesses.

- The effects of the as-deposited sample thickness on mechanical properties was less apparent in the SLM-processed specimens [13] as these were all given the same stress relief treatment prior to testing. The mechanical properties for both the flat and round samples stabilized after reaching a certain sample thickness.

- Values for the mechanical properties (tensile yield strength, ultimate tensile strength) are affected by differences in the microstructural features, including the $\alpha$-lamellae thickness, amount and type of porosity, and the width of the prior-beta grains. Both metallography and fractography analyses were conducted in this regard.

- The results obtained for the as-deposited vs. machined samples revealed that the mechanical properties were mostly affected by the as-deposited (i.e., rough) sample surfaces present for the as-deposited samples. However, testing of the machined samples revealed a more significant role of the microstructural differences on the subsequent mechanical properties.

- The results for both as-deposited and machined M-TT samples of Ti-6Al-4V are broadly useful for estimating the effects of changes in sample thickness, orientation, and processing technique(s) on mechanical properties, and are broadly relevant to such issues on components/parts. 
Author Contributions: Conceptualization, K.M. and J.D.; methodology, K.M. and J.D. and M.D. and M.R.; formal analysis, M.S. and J.J.L.; investigation, K.M. and J.D. and M.R. and M.D.; writing-original draft preparation, K.M. and M.R.; writing - review and editing, K.M. and J.D. and J.J.L.; visualization, K.M. and J.D..; supervision, J.D.; project administration, J.D. and M.S. and J.J.L. and D.V.; funding acquisition, J.D. and M.S. and J.J.L. and D.V. All authors have read and agreed to the published version of the manuscript.

Funding: The paper was realized due to the support of project EF17_048/0007350 - Pre-Application Research of Functionally Graduated Materials by Additive Technologies (2018-2022, MSM/EF), The Ministry of Education, Youth and Sports. Support for one of the authors (J.J.L.) was provided by the Arthur P Armington Professorship in Engineering at CWRU.

Conflicts of Interest: The authors declare no conflict of interest.

\section{References}

1. Srinivas, M.; Babu, B.S. A Critical Review on Recent Research Methodologies in Additive Manufacturing. Mater. Today Proc. 2017, 4, 9049-9059. [CrossRef]

2. Harun, W.; Kamariah, M.; Muhamad, N.; Ghani, S.A.C.; Ahmad, F.; Mohamed, Z. A review of powder additive manufacturing processes for metallic biomaterials. Powder Technol. 2018, 327, 128-151. [CrossRef]

3. Niinomi, M.; Nakai, M.; Hieda, J. Development of new metallic alloys for biomedical applications. Acta Biomater. 2012, 8, 3888-3903. [CrossRef] [PubMed]

4. Bose, S.; Ke, D.; Sahasrabudhe, H.; Bandyopadhyay, A. Additive manufacturing of biomaterials. Prog. Mater. Sci. 2018, 93, 45-111. [CrossRef]

5. Attar, H.; Calin, M.; Zhang, L.-C.; Scudino, S.; Eckert, J. Manufacture by selective laser melting and mechanical behavior of commercially pure titanium. Mater. Sci. Eng. A 2014, 593, 170-177. [CrossRef]

6. Sallica-Leva, E.; Jardini, A.; Fogagnolo, J.B. Microstructure and mechanical behavior of porous Ti-6Al-4V parts obtained by selective laser melting. J. Mech. Behav. Biomed. Mater. 2013, 26, 98-108. [CrossRef]

7. Lewandowski, J.J.; Seifi, M. Metal Additive Manufacturing: A Review of Mechanical Properties. Annu. Rev. Mater. Res. 2016, 46, 151-186. [CrossRef]

8. Frazier, W.E. Metal Additive Manufacturing: A Review. J. Mater. Eng. Perform. 2014, 23, $1917-1928$. [CrossRef]

9. Nguyen, D.S.; Park, H.S.; Lee, C.M. Optimization of selective laser melting process parameters for Ti-6Al-4V alloy manufacturing using deep learning. J. Manuf. Process. 2020, 55, 230-235. [CrossRef]

10. Sun, W.; Ma, Y.; Huang, W.; Zhang, W.; Qian, X. Effects of build direction on tensile and fatigue performance of selective laser melting Ti6Al4V titanium alloy. Int. J. Fatigue 2020, 130, 105260. [CrossRef]

11. Hrabe, N.W.; Quinn, T.P. Effects of processing on microstructure and mechanical properties of a titanium alloy (Ti-6Al-4V) fabricated using electron beam melting (EBM), part 1: Distance from build plate and part size. Mater. Sci. Eng. A 2013, 573, 264-270. [CrossRef]

12. Safdar, A.; He, H.; Snis, A.; De Paz, L.E.C.; Wei, L.-Y. Effect of process parameters settings and thickness on surface roughness of EBM produced Ti-6Al-4V. Rapid Prototyp. J. 2012, 18, 401-408. [CrossRef]

13. Dzugan, J.; Seifi, M.; Prochazka, R.; Rund, M.; Podany, P.; Konopík, P.; Lewandowski, J. Effects of thickness and orientation on the small scale fracture behaviour of additively manufactured Ti-6Al-4V. Mater. Charact. 2018, 143, 94-109. [CrossRef]

14. Phutela, C.; Aboulkhair, N.T.; Tuck, C.; Ashcroft, I. The Effects of Feature Sizes in Selectively Laser Melted Ti-6Al-4V Parts on the Validity of Optimised Process Parameters. Materials 2019, 13, 117. [CrossRef]

15. Rund, M.; Prochazka, R.; Konopík, P.; Dzugan, J.; Folgar, H. Investigation of Sample-size Influence on Tensile Test Results at Different Strain Rates. Procedia Eng. 2015, 114, 410-415. [CrossRef]

16. Razavi, S.; Van Hooreweder, B.; Berto, F. Effect of build thickness and geometry on quasi-static and fatigue behavior of Ti-6Al-4V produced by Electron Beam Melting. Addit. Manuf. 2020, 101426. [CrossRef]

17. Pehlivan, E.; Roudnicka, M.; Dzugan, J.; Koukolikova, M.; Králík, V.; Seifi, M.; Lewandowski, J.J.; Dalibor, D.; Daniel, M. Effects of build orientation and sample geometry on the mechanical response of miniature CP-Ti Grade 2 strut samples manufactured by laser powder bed fusion. Addit. Manuf. 2020, 101403. [CrossRef]

18. Sepe, R.; Franchitti, S.; Borrelli, R.; Di Caprio, F.; Armentani, E.; Caputo, F. Correlation between real geometry and tensile mechanical behaviour for Ti6Al4V electron beam melted thin specimens. Theor. Appl. Fract. Mech. 2020, 107, 102519. [CrossRef] 
19. Prochazka, R.; Dzugan, J. Strain controlled cyclic tests on miniaturized specimens. IOP Conf. Ser. Mater. Sci. Eng. 2017, 179, 12060. [CrossRef]

20. Dzugan, J.; Sibr, M.; Konopík, P.; Prochazka, R.; Rund, M. Mechanical properties determination of AM components. IOP Conf. Ser. Mater. Sci. Eng. 2017, 179, 12019. [CrossRef]

21. ASTM WK49229. New Guide for Orientation and Location Dependence Mechanical Properties for Metal Additive Manufacturing; Work in Progress; ASTM WK49229: West Conshohocken, PA, USA.

22. Ahmed, T.; Rack, H. Phase transformations during cooling in $\alpha+\beta$ titanium alloys. Mater. Sci. Eng. A 1998, 243, 206-211. [CrossRef]

23. Rafi, H.K.; Karthik, N.V.; Gong, H.; Starr, T.L.; Stucker, B.E. Microstructures and Mechanical Properties of Ti6Al4V Parts Fabricated by Selective Laser Melting and Electron Beam Melting. J. Mater. Eng. Perform. 2013, 22, 3872-3883. [CrossRef]

24. Tan, X.; Kok, Y.; Toh, W.Q.; Tan, Y.J.; Descoins, M.; Mangelinck, D.; Tor, S.B.; Leong, K.F.; Chua, C.K. Revealing martensitic transformation and $\alpha / \beta$ interface evolution in electron beam melting three-dimensional-printed Ti-6Al-4V. Sci. Rep. 2016, 6, 26039. [CrossRef] [PubMed]

25. Yan, M.; Yu, P. An Overview of Densification, Microstructure and Mechanical Property of Additively Manufactured Ti-6Al-4V—Comparison among Selective Laser Melting, Electron Beam Melting, Laser Metal Deposition and Selective Laser Sintering, and with Conventional Powder. Sinter. Tech. Mater. 2015. [CrossRef]

26. Parthasarathy, J.; Starly, B.; Raman, S.; Christensen, A. Mechanical evaluation of porous titanium (Ti6Al4V) structures with electron beam melting (EBM). J. Mech. Behav. Biomed. Mater. 2010, 3, 249-259. [CrossRef] [PubMed]

27. Bandyopadhyay, A.; Espana, F.; Balla, V.K.; Bose, S.; Ohgami, Y.; Davies, N.M. Influence of porosity on mechanical properties and in vivo response of Ti6Al4V implants. Acta Biomater. 2010, 6, 1640-1648. [CrossRef] [PubMed]

28. Wang, X.; Xu, S.; Zhou, S.; Xu, W.; Leary, M.; Choong, P.; Qian, M.; Brandt, M.; Xie, Y. Topological design and additive manufacturing of porous metals for bone scaffolds and orthopaedic implants: A review. Biomaterials 2016, 83, 127-141. [CrossRef]

29. Fousova, M.; Vojtěch, D.; KUBÁSEK, J.; Jablonska, E.; Fojt, J. Promising characteristics of gradient porosity Ti-6Al-4V alloy prepared by SLM process. J. Mech. Behav. Biomed. Mater. 2017, 69, 368-376. [CrossRef]

30. Seifi, M.; Salem, A.A.; Satko, D.; Shaffer, J.; Lewandowski, J.J. Defect distribution and microstructure heterogeneity effects on fracture resistance and fatigue behavior of EBM Ti-6Al-4V. Int. J. Fatigue 2017, 94, 263-287. [CrossRef]

31. Fousova, M.; Vojtěch, D.; Doubrava, K.; Daniel, M.; Lin, C.-F. Influence of Inherent Surface and Internal Defects on Mechanical Properties of Additively Manufactured Ti6Al4V Alloy: Comparison between Selective Laser Melting and Electron Beam Melting. Materials 2018, 11, 537. [CrossRef]

32. Sun, Y.; Aindow, M.; Hebert, R.J. Comparison of virgin Ti-6Al-4V powders for additive manufacturing. Addit. Manuf. 2018, 21, 544-555. [CrossRef]

33. Sun, Y.; Aindow, M.; Hebert, R.J.; Sun, Y.; Aindow, M.; Hebert, R.J. Materials at High Temperatures The effect of recycling on the oxygen distribution in Ti-6Al-4V powder for additive manufacturing. Mater. High Temp. 2017, 3409, 1-8.

34. Tang, H.P.; Qian, M.; Liu, N.; Zhang, X.Z.; Yang, G.Y.; Wang, J. Effect of Powder Reuse Times on Additive Manufacturing of Ti-6Al-4V by Selective Electron Beam Melting. JOM 2015, 67, 555-563. [CrossRef]

35. Xu, W.; Brandt, M.; Sun, S.; Elambasseril, J.; Liu, Q.; Latham, K.; Xia, K.; Qian, M. Additive manufacturing of strong and ductile Ti-6Al-4V by selective laser melting via in situ martensite decomposition. Acta Mater. 2015, 85, 74-84. [CrossRef]

36. Sallica-Leva, E.; Caram, R.; Jardini, A.; Fogagnolo, J. Ductility improvement due to martensite $\alpha^{\prime}$ decomposition in porous $\mathrm{Ti}-6 \mathrm{Al}-4 \mathrm{~V}$ parts produced by selective laser melting for orthopedic implants. J. Mech. Behav. Biomed. Mater. 2016, 54, 149-158. [CrossRef]

(C) 2020 by the authors. Licensee MDPI, Basel, Switzerland. This article is an open access article distributed under the terms and conditions of the Creative Commons Attribution (CC BY) license (http://creativecommons.org/licenses/by/4.0/). 